\title{
Integrating Design Thinking With Applied Chemistry Education: An Empirical Study
}

Kevin Sheng-Kai Ma, MSc ${ }^{1,2}$, Chin-Feng Wan, PhD ${ }^{1, *}$

${ }^{1}$ Department of Medical Applied Chemistry, Chung Shan Medical University, Taichung, Taiwan; ${ }^{2}$ Department of Life Science, National Taiwan University

*Corresponding author: Chin-Feng Wan, PhD

\section{Introduction}

- An educational module on customized cosmetic product design (CCPD) following design thinking framework for applied chemistry education was developed.

- The purpose of this study was to evaluate the efficacy of this module and to identify factors modulating learning efficiency of the participating students.

\section{Methods}

- This program was an elective course designed for undergraduate students at Chung Shan Medical University ( $N=74)$ consisted of 16 two-hour sessions on CCPD plus hands-on experience following design thinking process for (1) empathising, (2) defining, (3) ideating, (4) prototyping, and (5) testing the designated scenario on cosmetic design

Students were required to write an assignment on practically designing a customized cosmetic product before the study designoriented sessions as an indicator of baseline performance.

- After the study design-oriented sessions, the students were required to write the same assignment without prior notice, as an indicator of post-intervention performance.

The pre- post- difference of the performance was one of the indicators of the success of the program. In addition,

questionnaires focusing on behavioral changes, awareness and confidence of mastering CCPD, were administered before and after the sessions.

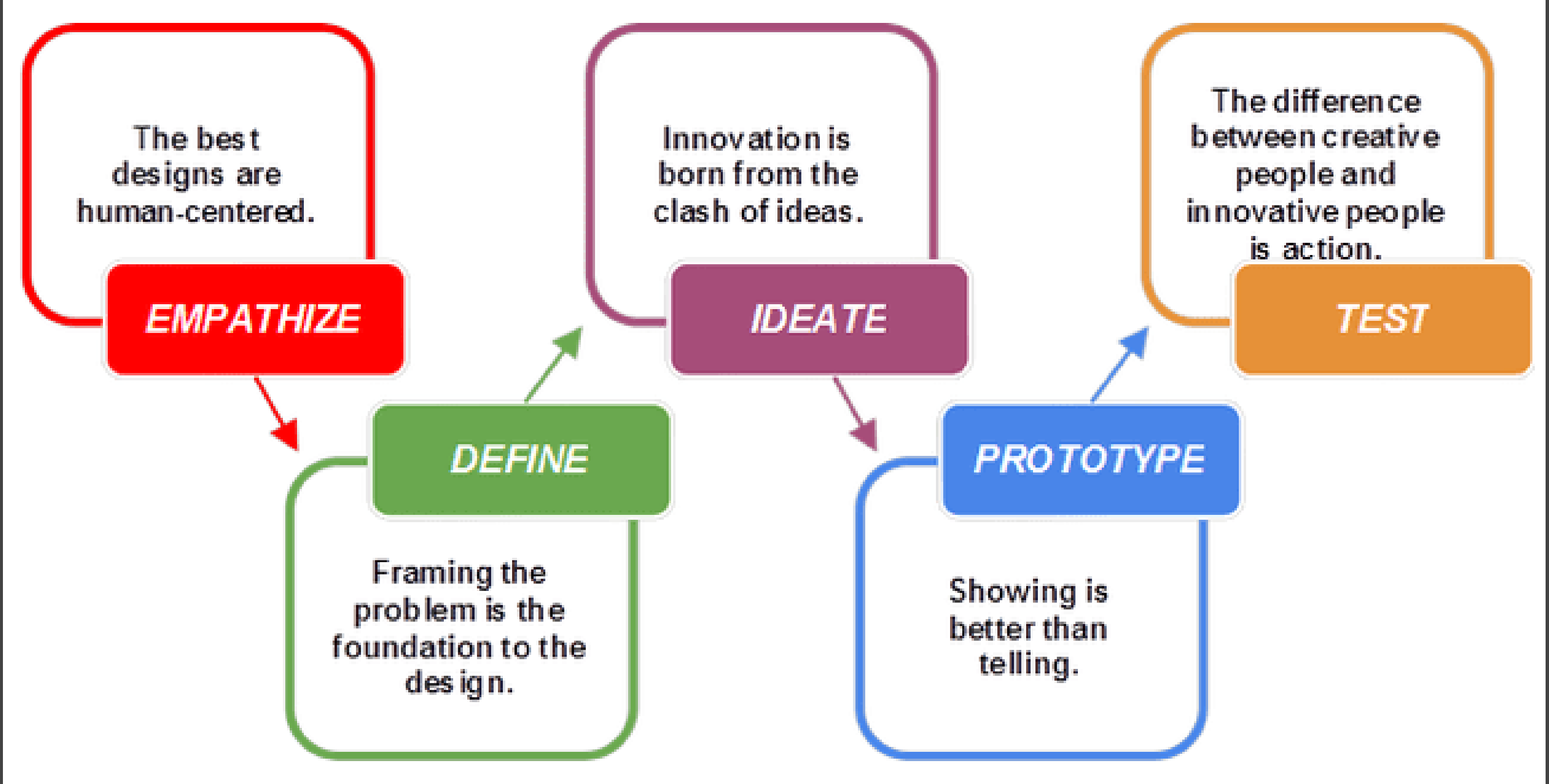

Figure 1. Flowchart for design thinking process
Table 1. Questionnaire for course evaluation. All questions were asked on a Likert scale from 1-7.

1 I actively participated in class and contributed to group projects.

I actively seek for opportunities to communicated and interact with classmates, and express my opinions.

I'm willing to help any classmate in course.

4 I study hard for all courses.

5 I know how to search scientific references.

6 I feel the contents of the course very interesting

7 attend all courses and attend on time.

8 I completed the assignments through hard working and on time.

9 I keep practicing and studying hard for this course.

10 I'm confident in my learning capabilities for this course.

11 I frequently practice critical thinking in class.

12 I have high learning efficiency.

13 I think the instructor used appropriate teaching techniques to achieve high teaching effectiveness.

14 I think the instructor taught contents that I was able to learn comprehend.

15 I think the instructor actively solve questions and problems that students are faced with.

16 Ithink the instructor interact with students with a respectful manner.

18 I'm willing to collaborate and cooperate.

19 I'm willing to actively seek help from classm

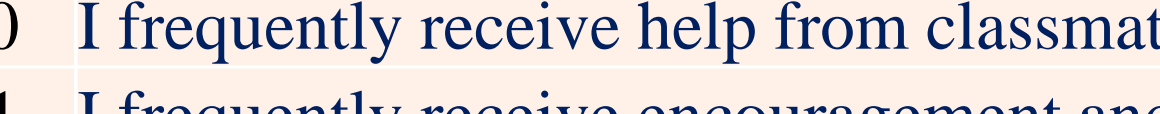

I know how do express my opinions.

23 I'm able to communicate and coordinate with groupmates when there are different opinions.

\section{Results}

We found evidence of better post-program assignment performance in utilizing CCPD-relevant concepts and resources $(P<0.05)$. Moreover, the participants reported increased awareness of CCPD $(P<0.05)$ and, behaviorally, increased utilization of CCPD-relevant resources $(P<0.05)$. Also, they reported improvement on appropriately using CCPD-relevant resources $(P<0.05)$ with strong confidence in practicing CCPD.

Objective performance of the course, as evaluated by the lecturers, was positively correlated with the scores of response to questions post-13 $\left(R^{\wedge} 2=0.09 ; \mathrm{P}=0.01\right)$ and $\mathrm{PO}-16\left(\mathrm{R}^{\wedge} 2=0.55 ; \mathrm{P}=\right.$ 0.04)

Attendance rate was positively correlated with the scores of response to questions post-9 $\left(R^{\wedge} 2=0.12 ; P=0.0034\right)$ and $P O-16\left(R^{\wedge} 2=0.08 ; P=0.01\right)$; and was negatively associated with the scores of response to pre-2 $\left(\mathrm{R}^{\wedge} 2=0.06, \mathrm{P}=0.04\right)$, $\mathrm{pre}-8\left(\mathrm{R}^{\wedge} 2=0.06, \mathrm{P}=0.03\right)$, and post- $4\left(\mathrm{R}^{\wedge} 2=0.12\right.$ $P=0.002)$

- Class participation was positively correlated with the scores of response to questions pre-2 $\left(R^{\wedge} 2=0.08 ; P=0.01\right)$, pre-3 $\left(R^{\wedge} 2=0.10 ; P=0.006\right)$, pre-4 $\left(R^{\wedge} Z=0.20 ; P<0.0001\right)$, pre-6 $\left(R^{\wedge} 2=0.18\right.$ $P=0.0001)$, pre- $7(R \wedge 2=0.08, P=0.01)$, pre- $9(R \wedge 2=0.06, P=0.03)$, mean of response to preintervention questionnaire $(\mathrm{R} \wedge 2=0.17 ; \mathrm{P}=0.0002)$, post $-2\left(\mathrm{R}^{\wedge} 2=0.06 ; \mathrm{P}=0.03\right)$, post 6 $\left(R^{\wedge} 2=0.14 ; P=0.001\right)$, and $P 0-17\left(R^{2} 2=0.06 ; P=0.03\right)$, and was negatively associated with the mean delta score of response to post- minus pre-intervention questionnaire $\left(\mathrm{R}^{\wedge} 2=0.08, \mathrm{P}=0.01\right)$.
Male sex was negatively correlated with the scores of response to questions pre-2 $\left(R^{\wedge} 2=0.07\right.$; $P$ $=0.02)$, pre-3 $\left(R^{\wedge} 2=0.14 ; P=0.001\right)$, pre-4 $\left(R^{\wedge} 2=0.1 ; P=0.006\right)$, and pre- $9\left(R^{\wedge} 2=0.12 ; P=0.003\right)$ and was positively associated with the score of response to $\mathrm{PO}-6\left(\mathrm{R}^{\wedge} 2=0.06, \mathrm{P}=0.03\right)$.

Table 2. Demographic data of participants ( $N=74$ )

\begin{tabular}{|c|c|c|c|}
\hline & Item & Number & Percentage \\
\hline Sex & Male & 30 & $32.43 \%$ \\
\hline \multirow{3}{*}{ Grade } & Female & 62 & $67.57 \%$ \\
\hline & 1 & 15 & $20.27 \%$ \\
\hline \multirow{3}{*}{ School } & 2 & 31 & $41.89 \%$ \\
\hline & 3 & 14 & $18.92 \%$ \\
\hline & 4 & 14 & $18.92 \%$ \\
\hline \multirow{3}{*}{ Attendance } & STEM & 30 & $40.54 \%$ \\
& Medicine & 10 & $13.51 \%$ \\
\hline & Paramedicine & 19 & $25.68 \%$ \\
\hline & Management & 15 & $20.27 \%$ \\
\hline & $100 \%$ & 42 & $56.76 \%$ \\
\hline & $85 \%$ & 22 & $29.73 \%$ \\
\hline & $70 \%$ & 7 & $9.46 \%$ \\
\hline & $55 \%$ & 1 & $1.35 \%$ \\
\hline
\end{tabular}

Pre-test responses vs post-test responses

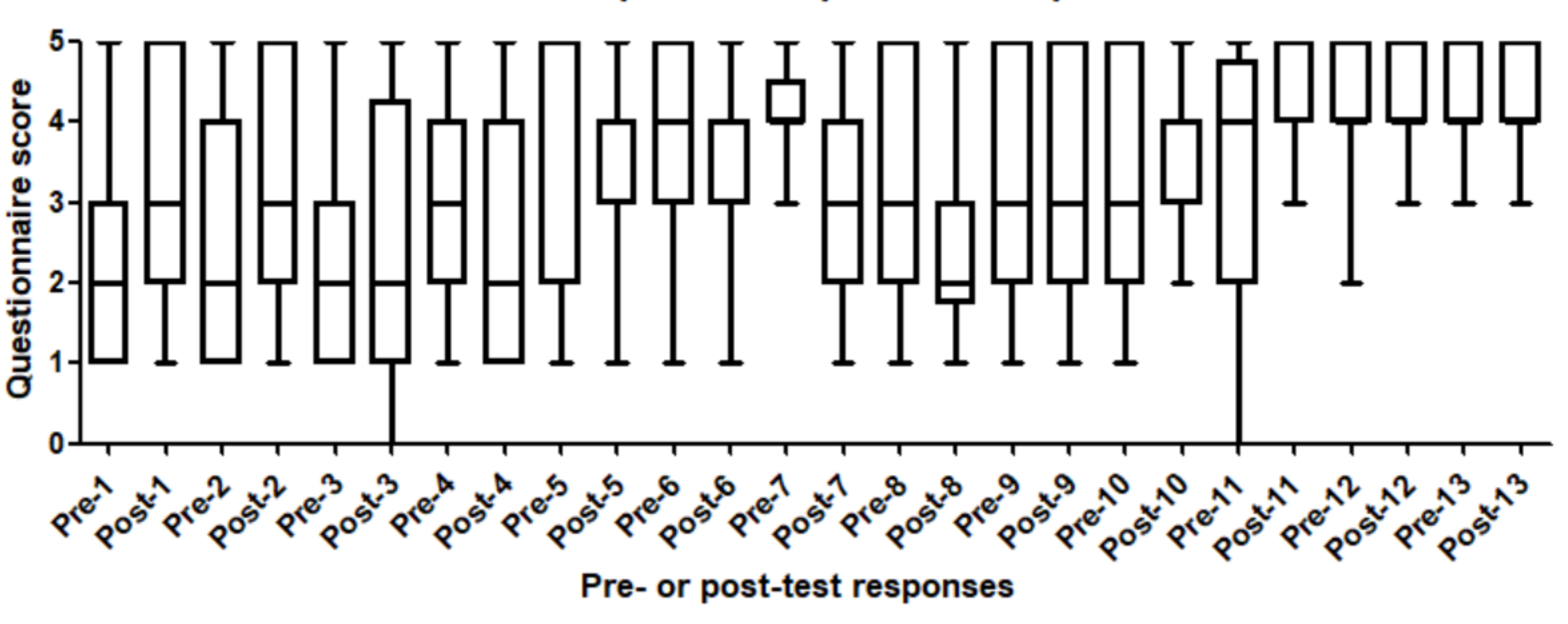

Figure 2. Student t-test of responses to questionnaires $(\mathrm{N}=74$ )

\section{Conclusion}

Modules on CCPD following design thinking process benefitted undergraduate students in scenario-oriented design thinking tutorials.

Keywords

Customized cosmetic product design, design thinking, applied chemistry, chemical education 